\title{
THE ROLE OF LESOTHO ACADEMIC LIBRARIES IN THE ATTAINMENT OF MDGS
}

\author{
Albert K. Kakoma \\ and \\ Lineo M. Mariti
}

\begin{abstract}
The role of tertiary institutions is to produce highly trained manpower for the country. They also provide leadership in different fields of development including community service. In all their endeavours the library plays a pivotal role through its provision of informational resources and related services. For the library to contribute positively to the training of this manpower it needs to have certain things in place without which the product of the institution will be lacking in some aspects. These are the products that go out into the field as agents of development.

This paper will specifically look at the challenges faced by libraries of higher institutions of learning in Lesotho and how they may adversely affect the realization of the Millennium Development Goals (MDGs). The focus will be on the libraries of the following tertiary institutions: National University of Lesotho (NUL), Lerotholi Polytechnic (LP), Lesotho College of Education (LCE), Lesotho Agricultural College (LAC) and the National Health Training Centre (NHTC). These are the major institutions of higher learning in the country. The need for addressing the challenges faced by the libraries of these institutions cannot be overemphasized.
\end{abstract}

Lesotho as a member of the United Nations Organization is committed to the attainment of the MDGs as agreed upon by the member states. For the government of Lesotho to succeed in the realization of the MDGs it needs assistance of all its institutions especially higher institutions of learning of which libraries are an integral part. Libraries in these institutions play important roles of not only stocking various information resources to be used by their clients but they also impart crucial information skills into the users. Both roles are important in the attainment of the MDGs.

Clearly libraries should play an active role in the realization of the MDGs. By addressing the challenges faced by academic libraries in Lesotho this paper attempts to find the way forward in attaining the MDGs in Lesotho. The paper also highlights some of the programmes currently being undertaken by some 
academic libraries in Lesotho that are inline with the efforts towards the attainment of MDGs.

Keywords: MDGs, attainment of MDGs, academic libraries, information literacy programme, higher education in Lesotho, challenges of academic libraries.

\section{Introduction}

Lesotho is a small mountainous country covering an area of 30, 355 square kilometres, of which only one quarter, in the west is lowland. The remaining three quarters consist of the highlands. The population of Lesotho is estimated to be 1.8 million (Lesotho Bureau of Statistics, 2006). However, more than half of the population living in rural areas is categorised as living in poverty, caused by factors such as drought, heavy snowfall and HIV/AIDS pandemic.

Lesotho is a proud signatory to the Millennium Declaration, which was adopted by 189 UN member states and signed by 147 heads of state and governments during the UN Millennium Summit in September 2000. The Government of Lesotho is committed to the achievement of the Millennium Development Goals (MDGs). The MDGs are drawn from the actions and targets contained in the Millennium Declaration (UN, 2000). These MDGs which are eight in number are:

- Goal 1: Eradicate extreme poverty and hunger

- Goal 2: Achieve universal primary education

- Goal 3: Promote gender equality and empower women

- Goal 4: Reduce child mortality

- Goal 5: Improve maternal health

- Goal 6: Combat HIV/AIDS, malaria, and other diseases

- Goal 7: Ensure environmental sustainability

- Goal 8: Develop a global partnership for development (UN, 2005).

In addressing the ways and means of achieving the MDGs the Government of Lesotho has come up with pertinent strategies. For instance the Government has a vision of attaining universal primary education by 2015. It has also developed relevant documents such as the "Vision 2020" (Ministry of Finance and Development Planning, 2004) and "Poverty Reduction Strategy" (PRS) which lasted 
from 2004 to 2007. Thereafter, the government began a process of updating and upgrading PRS into Lesotho Strategy for Growth and Poverty Reduction (LSGPR) starting from the period 2008/2009 to 2012/2013 aimed at achieving sustained and accelerated economic growth (UNDP Lesotho, 2007a).

With support from the UN Country Team the Government of Lesotho has developed a database tool known as Maluti-Info. This database will be used in the dissemination and monitoring of the MDGs, LSGPR, National vision 2020 and the Lesotho National Development Goals indicators. The Maluti-Info database has been made accessible to policy makers, private sector, NGOs and academic institutions. Obviously the libraries of academic institutions are expected to play a crucial role in the use and marketing of the database (UNDP Lesotho, 2007b).

For the Government of Lesotho to succeed in the realization of the MDGs it needs the active support not only of its various ministries but also of its higher institutions of learning, which according to Lor \& Britz (2007:50-51) need to keep abreast of the changes in their environments. Needless to say, the higher institutions of learning are the producers of manpower upon which the successful implementation and monitoring of policies including those pertaining to MDGs depend. The role of the libraries of these institutions in the training programmes of their parent institutions cannot be overemphasized. Five academic libraries and challenges that they face vis-à-vis their contribution towards the realization of the MDGs in Lesotho are under the spotlight in this paper.

\section{Educational system of Lesotho}

The provision of education in Lesotho is largely carried out by the Government, the main churches and the community. However, determination of curricula and syllabuses is the responsibility of the Ministry of Education. The Lesotho Government (2000) indicates that ongoing revision of the education system takes place and policy directions include provision of the following:

- Opportunities to develop competencies and education programmes, cultural values and activities that enhance individual and social development

- Sufficient numbers of individuals equipped with the appropriate occupational, technical and managerial skills to enable them to participate in socioeconomic development

- Opportunities for continuing education through non-formal programmes in literacy and numeracy, and vocational and in-service training in private enterprises 
- Active, cooperative partnership between all parties concerned in education management and service provision, with expansion of the roles of family and community in school activities

- Enhanced access to education.

These policy directions are meant to improve the human resource from early stages of learning to late adulthood. Once the human resource has been empowered with information literacy skills then their participation in socioeconomic development is likely to take place.

Within Lesotho's education system there are three main levels of learning namely: Primary, Secondary and tertiary levels of education. As a cosmopolitan country, Lesotho admits children of all nationalities in its schools and tertiary institutions.

\subsection{Primary Education}

Primary education is free in government and church schools and runs from standard one to standard seven for children aged between six and thirteen. The offering of free education in Lesotho was effected by the Government of Lesotho in 2000 (Lesotho Government, 2000). Similar to the example given by Chiobe (2006) free primary education enables the majority of poverty stricken rural poor children and HIV/AIDS orphans countrywide to have access to primary education and thus building on the literacy rate of Lesotho. Successful completion of primary education leads to secondary schooling.

\subsection{Secondary Education}

Secondary education includes both junior and senior secondary schooling which takes five years to complete. The Examination Council of Lesotho administers the examination at junior and senior level. Successful completion of higher level of secondary education opens the doors for admittance into tertiary or higher education. This includes the five institutions of higher education around which the discussion of this paper partly revolves.

\subsection{Tertiary Education}

The third level of education offered in Lesotho is tertiary or higher education. This type of education is offered by higher education institutions such as the National University of Lesotho (NUL). The Lesotho College of Education (LCE) is mainly concerned with training of pre-school, primary school and secondary 
school teachers and it awards only certificates and Diplomas. The Lesotho Agricultural College (LAC) deals mainly with training in agriculture including Food production, Nutrition and Forestry. The LAC offers its programmes at undergraduate certificate and diploma levels. The Lerotholi Polytechnic (LP) provides technical and commercial training, which aims at meeting the demands of the local industry. The National Health Training Centre (NHTC) aims at training paramedics, nurses and social workers that will assist in the fight against HIV/AIDS pandemic and other common diseases. All five institutions of higher education are expected to produce quality graduates that will address the challenges facing Lesotho as they join the labour market. The UN system in Lesotho (2004:22) indicates that slow pace of job creation in the country has resulted in continuous poverty. McFarlane (2005:134) and Major (2005:18) are of the same opinion that the products of higher education institutions should be creators of jobs, not necessarily job-seekers, in order to foster development.

The administration and management of tertiary institutions is the responsibility of both the government and the concerned institution. The management and administration of the institution is run through the Senate, faculty boards and management committees. The main target of education in Lesotho is to attain universal basic education by meeting the demands for education for all (Lesotho Ministry of Education, 2006). The education programmes aim to address Lesotho's development requirements and to improve quality of products and the standard of living through efficiency, effectiveness and increased access to education (Kakoma, 1999). The government of Lesotho supports increased financial allocation to education and authorizes the National Manpower Development Secretariat division to effectively manage the scholarships (Lesotho Government, 2000).

The Government has made an effort to increase the number of universities within the country by allowing "Limkokwing University of Creative Technology" to establish a campus in Lesotho. This University was expected to be in full operation by June 2008 starting with six faculties (Lesotho Ministry of Education and Training, 2007).

\section{The five institutions}

The five higher institutions of learning whose libraries are the subject of this paper, are the major producers of skilled manpower in Lesotho. The government supports all the five institutions. These institutions are NUL, LAC, LCE, LP and NHTC. Each of the institutions offers various programmes and produces gradu- 
ates that are qualified in various fields and at various levels of training. The local job market absorbs most of the graduates. The following is brief information on each of the five institutions.

\subsection{The National University of Lesotho}

Currently the NUL is the only university in Lesotho. It was established in 1945 as a Catholic College (NUL Public Affairs Office, 2006:1). It has evolved over its sixty-three-year history and is now a fully-fledged university offering programmes ranging from certificate to $\mathrm{PhD}$ in various fields (NUL Academic Office, 2007). Presently the student population stands at over 7000 (NUL statistics Office, 2007). The library of the NUL is not only the biggest but also the best equipped, the best-stocked, and the best staffed academic library in Lesotho. Apart from the main University library there are also two documentation centres, belonging to the Institute of Education (IE) and Institute of Southern African Studies (ISAS) respectively. Both institutes are based on the main campus of NUL.

\subsection{Lesotho Agricultural College}

This institution offers sub-degree programmes in Agriculture, Forestry and Home Economics. It has two campuses, the main one in Maseru and the other one in Leribe. All in all, the college has a student population of 600 . It has a wellstocked library.

\subsection{Lesotho College of Education}

The Lesotho College of education offers programmes that lead to three subdegree qualifications. These qualifications are: Certificate in Early Childhood Education, Diploma in Primary Education and Diploma in Secondary Education. The college has 992 students. It has a spacious and well-stocked library.

\subsection{Lerotholi Polytechnic}

This institution offers technical and commercial programmes at sub-degree level (LP, 2004). The student population stands at 1620. The library is spacious and is quite well stocked. 


\subsection{National Health Training Centre}

Presently this institution offers only sub-degree programmes in Health Sciences. It has 410 students. The institution's library has just moved to newly erected purpose-built premises.

Out of the five libraries only one, the NUL Library, has a branch library. The branch library in question is based at the NUL's Institute of Extra-Mural Studies (IEMS). There are also plans to establish libraries at the three IEMS Centres situated in Mohales' Hoek, Mahobong in Leribe and Thaba-Tseka.

It is envisaged that when established, the libraries in all the IEMS centres will also serve users who will be undertaking training with the assistance of the Development Partnership for Higher Education (DelPHE) Project. This collaborative project sponsored by the Department for International Development (DFID) of the United Kingdom is a joint project run by the University of Dundee on the one hand and the NUL, specifically the Faculty of Health Sciences and the NUL Library on the other. The project will train health personnel through the distance education mode.

\section{The situation on the ground vis-à-vis the five libraries}

Like academic libraries elsewhere in the world as indicated by Mehra \& Srinivasan (2007:123), the libraries of the five institutions, as catalysts for change, are there to support mainly the learning, teaching and research activities of their parent institutions. They support the three activities in as many ways. First, by acquiring relevant information resources. This is done in consultation with the teaching departments. Secondly, making the materials available to the clients on long-term and/ or short-loan basis and through having adequate opening hours. The academic governing body of the institution of learning normally determines the opening hours. Thirdly, the clients have to be taught how to effectively use the various information resources. Consequently many academic libraries have introduced User Education programmes and/ or Information Literacy programmes. The user education programmes or the information Literacy programmes are aimed at equipping students with information-seeking skills. In other words, the programmes are meant to produce independent information seekers and users. This is crucial given the great need for life-long learning. Obviously the attainment of the MDGs is dependent, to some extent, on lifelong learning activities (Clouston, 2005:54-55). 
Clearly, the role of the management of the institution of higher learning must go beyond the exercise of erecting a library building. For any library to operate smoothly, it needs a reasonable annual financial allocation or budget. It also has to be adequately staffed. The need for the commitment of the institution's management towards the success of the functions of the library cannot be overemphasized.

\subsection{Enquiry}

As already stated the aim of this paper is to bring to the fore the challenges faced by libraries of higher institutions of learning in Lesotho. It is believed that these challenges impact negatively on the overall training offered in the institutions. This may in turn adversely affect the realization of the MDGs. In the quest for data librarians in the five institutions were asked the following questions:

- Do you know anything about MDGs?

- Does your library have deliberate efforts towards acquiring materials on MDGs?

- Does your library have materials related to the attainment of MDGs?

- Is your library automated?

- What is your library's annual budget for books and serials?

- What programmes are offered by the institution?

- Do you offer User Education/ information literacy programme?

- Is there any faculty-librarian collaboration?

- Does your library cooperate with other libraries in Lesotho?

- Do the students have any work-based learning programmes?

- Who are your library's clients?

- What are the challenges faced by your library?

In addition to the above questions some data had to be sourced or verified by observation and by consulting institutional documents in some cases. 


\subsection{Findings}

The following account constitutes the findings based on the responses to the questions. All but one (NHTC) responded in the affirmative to question 1. In response to question 2 only two libraries (NUL and LAC) stated that their libraries have deliberate efforts to acquire materials on MDGs. To question 3 all responded in the affirmative. It should be specially noted that even the libraries which responded in the negative to questions 1 and 2, responded in the affirmative to question 3 . This is so, because they acquired the materials through donations or through other default means. Upon further inquiries and discussions almost all librarians interviewed agreed that there was great need for their libraries to stock information resources on MDGs. They also agreed that they would undertake deliberate efforts to collect all the materials if not the pertinent ones, in order to meet the needs of their clients. Two librarians also indicated that many clients always inquire about the materials and they always refer them to other libraries especially NUL Library.

Automation or computerization of libraries of higher institutions of learning in Lesotho is yet to be undertaken by most institutions. Currently out of the five libraries only one (NUL) is automated. Of the remaining four, two (LCE and LP) are partially automated and the other two (LAC and NHTC) are not automated. Internet facilities are also hardly available in most of the libraries being looked at in this paper. It was stated that the lack of Internet facilities was frustrating to library users. The lack of current information resources such as academic journals in many of these libraries was supposed to be supplemented by library online databases such as EBSCO-host, HINARI, and AGORA. But the lack of both Internet and computers in these libraries means that clients cannot access online and off-line databases.

Financial support to most of the libraries is a source of concern. Apart from NUL library that has an annual allocation of over four million Maluti (M4, 000,000.00) for books and serials the rest receive much less than one million Maluti per year. As a matter of fact their financial allocations fluctuate from year to year. In short the four libraries do not have what may be termed as adequate budgets. Their acquisitions efforts are therefore adversely affected by this state of affairs. As a result librarians in these institutions are faced with the challenge of providing better services with grossly inadequate budgets. Given this unfavourable situation the librarians in the four institutions are of the view that their libraries should be allocated their own budgets which must be increased every year to cater for library inputs, outputs and outcomes. They emphasised the need to make presentations to relevant authorities. 
Once again it is only the NUL library whose parent institution offers programmes leading to qualifications ranging from certificate to $\mathrm{PhD}$. The remaining four libraries service mainly clients who pursue sub-degree programmes i.e. programmes leading to certificate and diploma qualifications. It is however important to note that most of the programmes offered are relevant to the realisation of the MDGs. This brings into focus the need for deliberate efforts by libraries to acquire materials on MDGs.

Three libraries (NUL, LAC, and LCE) responded in the affirmative to question 7 , which was on User education/ information literacy. Currently all the three libraries offer this as a Communication Skills module of the first year compulsory English Course. However, the LP Librarian lectures to students about the library only during orientation or when requested by individual lecturers. All respondents agreed that information literacy is very important and were unanimous on the need to make it an integral part of the curricula of institutions of higher learning. This will enable the institutions to produce lifelong learners who are skilled information users.

Only one librarian (NHTC) responded in the negative to question 8. For those who responded in the affirmative (NUL, LCE, LAC and LP) they said they collaborated with faculty in the selection of books, training of students in library use, and faculty members are part of the library committee among other things. Strangely the librarian for the NHTC was the only one who answered in the negative to question 9, stating that the NHTC Library did not have any relationship with other libraries in Lesotho. This is strange given the fact that no library is self-sufficient hence the need for library cooperation through associations and consortia. The NHTC librarian was aware of the existence of the Lesotho Library Association (LLA) and the Lesotho Library Consortium (LELICO) but neither she nor her library participated in the activities of both bodies. The librarian regretted this situation and realised the need to correct it.

To question 10 all respondents stated that the students in those institutions have work-based learning programmes. These include attachments, fieldwork, teaching practice, etc. These programmes expose students to various societal needs. The respondents generally agreed that work-based learning should be maintained by all institutions of higher learning because it provides creativity which involves critical thinking and greater responsibility.

All the respondents gave a similar answer to question 11. They stated that their main clients were students, staff and researchers. This is inline with the stipu- 
lated role of their libraries which is mainly to support learning, teaching and research activities of their mother institutions.

The last question (12) was on the challenges faced by these libraries. Some of the challenges such as lack of computerisation and lack of information literacy programmes have already been stated. Inadequate budgets and poor staffing situation also rank high in the list of challenges. For instance the NHTC and LAC libraries are run by Para-professionals (both are diploma holders). It is a serious oversight that libraries of such big institutions could be run by para-professionals however efficient they may be. Definitely, with this calibre of staff in charge the full potential of those libraries will never be realised.

\section{Challenges vis-à-vis attainment of MDGs}

The five institutional libraries being looked at in this paper service training and learning programmes of institutions that produce most of the manpower for Lesotho. Needless to say, the produced manpower is in various fields. The graduates of these institutions are supposed to be the agents of change in the various communities that they serve. It goes without saying that the attainment of MDGs is to a greater extent dependent on the participation of the graduates from these institutions.

It is a fact that the library plays, or is supposed to play a crucial role in the training of a student. This is the reason why the library occupies the central part in the philosophy of a learning institution. The modern academic library does not only stock information resources but it must also be pro-active in ensuring that clients are aware of the resources and that the resources are used. Among its other functions are carrying out orientation programmes and conducting user education and/ or information literacy classes. By embarking on such exercises the library is playing the important role of equipping the students with informationseeking skills. These skills come in handy even after the students have left the institution of learning.

For the library to succeed in its functions it has to be adequately supported. This support should be in the form of adequate space, financial resources for acquisition of information resources and equipment, above all adequate staffing in terms of numbers and training. Definitely all efforts, however good meaning they may be, will be futile if the staffing component is overlooked. All these are lacking in acceptable quantities and quality in most of the libraries dealt with in this paper. 
It is not an over-statement to point out that most of the libraries as shown in the previous section have serious challenges in terms of inadequacies. Consequently, most of the graduates leave the institutions without information skills, which are crucial to lifelong learning. Similarly, due to inadequate pertinent resources in these libraries most graduates are not aware of the MDGs and of the role they are supposed to play in relation to their attainment.

\section{Library projects and MDGs}

One wonders whether it is by design or not that the NUL library hosts three major projects that coincidentally are related to MDGs. But given the "best supported" status that it enjoys in the country the NUL Library had to host projects. One of these projects also mentioned by Nelson \& Farrington (1994:21) is the Question and Answer service (QAS) of the Technical Centre for Agricultural and Rural Cooperation (CTA), which provides answers to questions by farmers and agricultural workers. The other one is the DelPHE project which is a collaborative initiative between the University of Dundee and NUL, aimed at training health workers based in different parts of Lesotho through the long distance learning mode. The third and final project is the Lesotho Development Information Centre (LDIC). This centre receives and makes available to clients information resources from cooperating partners. The partners are: The World Bank, National University of Lesotho, Food and Agricultural Organisation of the United Nations, United Nations Children's Fund, World Health Organisation and United Nations HIV/AIDS.

The LDIC is a partnership initiative of the World Bank and other development agencies that are active in Lesotho. It was established in 2005 at the NUL main library to promote the use of and access to development knowledge and to improve the effectiveness of development programmes in Lesotho. The centre, which is open to the general public, researchers, policy makers, and students, has an abundant and ample source of development information.

Compared with the other four libraries the NUL is steps ahead in terms of contributions towards the attainment of MDGs. Its aggressive weekly collection trips to government departments, publishing houses, and to all likely sources of publications has helped it to acquire numerous publications on MDGs besides the ones donated to the DIC. Unfortunately, for inexplicable reasons the other four libraries do not have a similar acquisition strategy. As a result their collections of information resources about MDGs are quite minimal. This does not augur well for these libraries because their clients specifically students are disad- 
vantaged by not having access to a wide range of materials on MDGs. What more that the attainment of MDGs is a topical subject in Lesotho.

\section{Observations and conclusions}

The attainment of MDGs is the ultimate desire or aim of all the signatory states. To achieve this aim countries such as Lesotho need the support of all and sundry especially higher institutions of learning whose libraries should play an active role in the area of information provision. The current situation in the Lesotho libraries of higher institutions of learning vis-à-vis MDGs call for more concerted efforts. The paper has highlighted a number of constraints inhibiting the expected levels of support from these libraries to the efforts towards the attainment of MDGs in Lesotho. Among the most serious inhibitions being faced by some of the librarians are poor staffing situation, inadequate budgets, lack of automation and lack of computers for Internet services. These are serious problems, which require the attention of those in charge of the parent institutions. Clearly, the individual librarians in those institutions need the assistance of the Library Association for the message to be heard and taken seriously. Otherwise this state of affairs in which these libraries are, will continue year in and year out.

\section{References}

Chiombe, E. 2006. Challenges 2006 -2007: Lesotho edging towards education MDGs. Online. Available: http://ipsnews.net (Accessed 12 June 2008).

Clouston, T.J. 2005. Facilitating tutorials in problem-based learning: students' perspectives. In: Hartley, p., Woods, A. and Pill, M. (eds). Enhancing teaching in higher education: new approaches for improving student learning. London: Routledge. p.48-58.

Kakoma, A.K. 1999. School libraries in Lesotho. Information Development, 15(2):120-125.

Lerotholi Polytechnic (LP). 2004. Lerotholi Polytechnic academic year almanac for 2004/2005. Maseru: Lerotholi Polytechnic.

Lesotho Bureau of Statistics. 2006. National statistics: population census results 2006. [Online]. Available: http://www.bos.gov.ls (11 April 2008). 
Lesotho government. 2000. Lesotho education. [Online]. Available: http://www. lesotho.gov.ls/about/education.php (Accessed 27 March 2008).

Lesotho Ministry of Education and Training. 2007. LIMKOKWING university of creative technology wants to establish a campus in Lesotho. [Online]. Available: http://www.education.gov.ls (Accessed 27 March 2008).

Lesotho Ministry of Education and Training. 2006. Education for all. Online. Available: http://www.education.gov.ls (Accessed 27 March 2008).

Lesotho Ministry of Finance and Development Planning. 2004. Lesotho vision 2020: empowerment for prosperity. Morija: Morija Printing Works.

Lor, P. \& Britz, J. 2007. Challenges of the approaching knowledge society: major international issues facing LIS professionals. Libri: international journal of libraries and information services, 57(3):111-122.

Major, D. 2005. Learning through work-based learning. In: Hartley, p., Woods, A. and Pill, M. (eds). Enhancing teaching in higher education: new approaches for improving student learning. London: Routledge. p.16-25.

McFarlane, K. 2005. Learning about employability. In: Hartley, P., Woods, A. \& Pill, M. (eds). Enhancing teaching in higher education. London: Routledge. p.133-144.

Mehra, B. \& Srinivasan, R. 2007. The library-community convergence framework for community action: libraries as catalysts of social change. Libri: international journal of libraries and information services, 57(3):123-139

National University of Lesotho (NUL) Academic Office. 2007. Qualifications or subject list for academic year 2007. (Unpublished).

National University of Lesotho (NUL) Statistics Office. 2007. Enrolment by faculty by year: postgraduate and undergraduate statistics for academic year 2006/07. (Unpublished).

National University of Lesotho (NUL) Public Affairs Office. 2006. National University of Lesotho 2006/07 calendar. Roma: NUL Public Affairs Office. 
Nelson, J. \& Farrington, J. 1994. Information exchange networking for agricultural development: a review of concepts and practices. Netherlands: Technical Centre for Agricultural and Rural Cooperation (ACP-EEC). Exeter: Sayce.

United Nations (UN). 2000. United Nations millennium declaration (A/55/L.2). Online Available: http:// www.un.org/millennium/declaration/ares552e.pdf (Accessed 03/ April 2008).

United Nations (UN). 2005. UN millennium development goals. [Online]. Available: http://www.un.org/millenniumgoals/goals.html (Accessed 03 April 2008).

United Nations Development Programme Lesotho (UNDP Lesotho). 2007a. UNDP supports Lesotho's MDG-based strategy for growth and poverty reduction. [Online]. Available: http://www.undp.org.ls/news/MDG\%20based20\%PRS. php (Accessed 08 April 2008).

United Nations Development Programme Lesotho (UNDP Lesotho). 2007b. Database Administrator. [Online]. Available: http://www.undp.org.ls/jobs/Database TrainingAss.php (Accessed 08 April 2008).

United Nations (UN) System in Lesotho. 2004. Common country assessment of Lesotho: December 2004 report. Morija: Morija Printing Works. 
